\title{
A ampliação do conteúdo de aprendizagem segundo os Padres da Igreja
}

\author{
Expanding Learning content according to Church Fathers
}

\section{Resumo}

Os Padres da Igreja, enquanto se tornaram grandes comentadores do Antigo e do Novo Testamento, promoveram muitos projetos com a preocupação em construir fórmulas importantes para os dogmas cristãos, especialmente graças à relação com a cultura helênica, de que desenvolveram um grupo de instruções e regras amplamente compatíveis não apenas com o processo de hermenêutica bíblica, mas sobretudo com a habilidade de compreender ou dar testemunho dos seus próprios escritos e pensamentos. Juntos, escritores cristãos de diferentes lugares como Roma, Alexandria e Hipona deixaram para a Ciência da Educação vestígios da sua própria experiência, dos quais nada impediria as pesquisas hodiernas de tirar proveito. Este artigo enumera a técnica da inventio, onde normalmente buscavam o assunto a ser tratado, o processo de aprendizagem e de conhecimento e, finalmente, o crescimento do conteúdo de acordo com a paideia cristã antiga.

Palavras-chave: Patrística. Educação. Conhecimento. Hermenêutica.

\section{Abstract}

As great commenters on both Old and New Testament, the Fathers of the Church carried out many projects in the effort to build important formulas for the Christian dogmas, thanks especially to the approach to Hellenic culture, from which they developed a group of instructions and rules widely compatible not only with the biblical hermeneutic process, but above all with the ability either to understand or to give witnesses of their writings and thoughts. Together writers from different places as Rome, Alexandria and Hippo let for the Science of Education clues of their own experiences, on which nothing would prevent

\footnotetext{
a Pontifícia Universidade Católica do Rio de Janeiro (PUC-Rio), Rio de Janeiro, RJ, Brasil. Doutor em Ciência e Teologia Patrística, e-mail: leleur@yahoo.it
} 
today's research to make profit. This article enumerates the technic of inventio, where they usually looked for the subject to be treated, the process of learning or acknowledgment and finally the growing of the content in accordance to the ancient Christian paideia.

Keywords: Patristics. Education. Acknowledgement. Hermeneutics.

\section{Introdução}

Um número considerável de estudos recentes têm colaborado para que haja mais atenção ao material produzido no período patrístico, destacando o dinamismo das estruturas literárias gregas e latinas dentro de um universo bem mais amplo do que aquele da constituição dogmática e histórica do cristianismo nascente. De fato, além de figurarem entre os mais nobres e importantes nomes da formação do pensamento cristão, os Padres da Igreja podem ser citados no elenco dos sábios e dos construtores do saber da história da humanidade em virtude da sua grande contribuição para a teologia, a exegese, a catequese, a liturgia, a oração, a caridade e a vida espiritual - a saber - agrupando de maneira eficaz tudo aquilo que se espera do conceito "sabedoria" (LONGOBARDO, 2000, p. 11).

Cronologicamente, nós selecionamos os textos de Justino de Roma (+165), de Clemente de Alexandria (+215), Orígenes de Alexandria (+253) e Agostinho de Hipona (+430) para recolher de sua documentação breves instrumentos úteis para avaliação relacionada à produção do conhecimento, trazendo para o contexto acadêmico atual conceitos que possam contribuir para o crescimento natural da pesquisa científica e levando em consideração as propostas do espírito que motivaram a teologia pré- e pós-conciliar ao retorno às fontes patrísticas. Tal método foi sustentado pela Optatam Totius de onde se aufere que as Sagradas Escrituras, a Patrística e a Escolástica são fontes primordiais para alcançar as soluções para os problemas humanos (OT 16), sejam eles quais forem. Cumprem-se, neste estudo, enfoques exegéticos e hermenêuticos dos Padres da Igreja.

Para melhor nos familiarizarmos com tal exposição, é importante notar que a normativa gnosiológica, correspondente à Teoria do Conhecimento na Filosofia, era objeto permanente de reflexão dos nossos autores.

Metodologia 
Damos continuidade à nossa linha de pesquisa cuidando das informações eclesiástico-institucionais do período patrístico. Abre-se um diálogo entre a paideia antiga e a instrução da educação moderna tendo como ponto de partida os comentários que os Padres da Igreja transmitiram em obras que se tornaram clássicas para vida da Igreja e confiando na antiguidade, credibilidade e fecundidade de tal conteúdo. Explora-se, com isso, aspectos necessariamente extra-dogmáticos que não se reduzem a apenas uma área de conhecimento. Desenvolvemos, assim, um diálogo interdisciplinar, reconhecendo as mesmas bases filosóficas e culturais presentes em diversos campos do saber. O conhecimento, nesse sentido, é interpretado de maneira mais abrangente; sua aquisição denota sempre a possibilidade de ampliá-lo numa dinâmica de humanização da existência, conforme nos indica a Fides et Ratio 3 (JOÃO PAULO II, 1999, p. 8). Escolhemos, então, compreender o assunto em três momentos da produção do conhecimento: a origem, o progresso e a ampliação do conteúdo.

\section{A origem do conteúdo}

Os Padres da Igreja foram educados e instruídos, seguindo os grandes manuais da paideia e da retórica antiga. Em uma famosa citação do De Trinitate de Agostinho, encontramos uma importantíssima referência à educação retórica. Diz o santo hiponense:

Na questão sobre a Trindade e sobre o conhecimento de Deus, aquilo que devemos indagar não pode ser outra coisa a não ser sobre o verdadeiro amor, ou melhor, sobre o que seja o amor, porque não há amor digno de tal nome que não seja aquele verdadeiro (De Trinitate $8,7,10$ ).

Mais à frente, retoma sua observação:

Quando perguntamo-nos sobre o que seja o amor a não ser uma vida que une e que tende a unir dois seres, ou seja, aquele que ama e aquele que é amado, não foi ainda encontrado o que se procura, mas já foi encontrado onde alguém o deve encontrar (De Trinitate 8, 7, 14).

Vale a pena perceber que, com este modo de falar, os Padres da Igreja abordavam diretamente o tema do conhecimento no que diz respeito à primeira parte da retórica. De fato, os antigos usavam o termo latino inventio para mostrar aos seus discípulos o ponto de partida para uma boa 
argumentação. Segundo Lausberg, a inventio era a primeira fase da elaboração das ideias, em que a sua construção não se caracterizava tanto pela capacidade de inovação ou brilhantismo, mas sobretudo pela individualização de esquemas de ideias elementares que servissem como instrumentos intelectuais e afetivos para a persuasão da audiência e do juiz, no caso dos gêneros deliberativos (LAUSBERG, 2002, p. 30).

Em termos atuais e seguindo a estrutura pedagógica das instituições mais privilegiadas do mundo, grande parte da sociedade acadêmica prevê a invenção como algo propriamente raro, como consequência de acúmulos de informações que produzam um jeito inédito de se argumentar sobre algum conteúdo e, mais raro ainda, um método de aplicação para o mesmo conteúdo que se possa verificar repetidamente. A professora Marta Valentim demonstra com bastante precisão que, no processo moderno de formação de conhecimento, o insight é considerado na parte superior de um prisma cuja base e antecedentes sejam a agregação de dados, o processamento de informações, a interpretação de conhecimentos explícitos e, enfim, se não estivermos errados em nossa interpretação, o movimento próprio que ela chama de pensamento (VALENTIM, 2010, p. 322). De qualquer forma, esse modo de produzir conhecimento prevê que a invenção ou o insight estejam escalonados na parte conclusiva do processo de conhecimento, como se apenas nos termos de um percurso de uma vida inteira alguém fosse capaz de, então, afirmar algo válido em virtude do conhecimento e da experiência acumulados. Bernard Lonergan escreveu um livro importante intitulado Insight para tratar do conhecimento humano. Neste livro, Lonergan cita Arquimedes de Siracusa, um matemático do terceiro século antes de Cristo, para explicar que o insight é a postulação da descoberta - a famosa eureca - do conhecimento reflexivo, ou seja, a conclusão do conhecimento (LONERGAN, 2007, p. 375).

De modo completamente contrário, as duas afirmações de Agostinho de Hipona com as quais começamos a tratar este assunto, ao invés de supor a inventio como fim ou como conclusão do processo, em harmonia com os manuais de retórica, tratam-na como início, como sugere o próprio nome. A palavra inventio deriva-se do verbo latino invenio, que corresponde, em português, verbo encontrar ou vir a certo destino, no sentido de ter vindo ou 
chegado a alguma descoberta ou conclusão. Neste caso, os instrumentos de que dispunham os alunos eram normalmente questões preliminares que os ajudavam a concentrar-se sobre a análise do objeto em questão. Reboul diz que as questões retóricas que compunham a inventio eram: quem?, quando?, contra quem?, por quê?, como? (REBOUL, 2003, p. 164). É curioso que depois de terem sido modificados o número e a ordem destas perguntas, elas reapareceram em teorias atuais de marketing e publicidade (KOEKEMOER; BIRD, 2004, p. 41).

Para Agostinho, a origem do conhecimento não é necessariamente a conclusão de um pensamento, mas é a descoberta de elementos que apoiem e garantam a segurança de uma reflexão. Por ser um grande defensor do conteúdo dogmático, Agostinho opõe-se a inovações que resultem de um processo emancipado da reflexão anterior e tradicional. No entanto, isso não significa que ele mesmo não venha a se tornar um dos grandes protagonistas da inventio, postulando ideias criativas e inteligentes ao lado de soluções esclarecedoras para os desafios de sua época. Voltaremos a essas soluções daqui a pouco.

Ainda falando sobre a origem do conhecimento, nos perguntamos como um aluno de graduação poderia ser favorecido pela maneira patrística de pensar. É importante observar que, naquela citação do De Trinitate, Agostinho só use uma das questões da inventio, ou seja, “o que é isso?”, sem que tenha que responder a outras questões que a retórica postulava. É precipitado que alguém diga que, por isso, para Agostinho, a melhor das perguntas a se fazer seja "que é isso?", como, a princípio, é a primeira intenção da dialética antiga (Cf. GONZÁLEZ, 1998, p. 88). Na nossa opinião, esse pode ser um modo de se expressar que julga como o aluno ou o escritor precisa ter consciência de um ponto de partida seguro, pelo qual suas afirmações possam encontrar soluções fáceis diante dos desafios que a reflexão sugere.

Neste sentido, duas sugestões de Agostinho se tornam relevantes, por ele ter tratado do assunto no De doctrina Christiana. Numerosos sãos os elementos pedagógicos apresentados por Agostinho neste livro. No segundo livro desta obra, o Doutor de Hipona adverte aos seus leitores sobre a importância de perceber o gênero de linguagem usado nos livros que estes costumavam ler (De doctrina Christiana II, 5, 6). Ademais, propõe prudência em 
relação aos textos difíceis (Id. II, 6, 7). Acreditamos que estes dois conselhos ainda sejam válidos para o nosso tempo. Em primeiro lugar, toda ciência ou toda área acadêmica produz o seu conhecimento a partir de estruturas de linguagem específicas. É importante que cada profissional, além da capacidade de dominar o seu idioma, tenha clareza sobre os gêneros literário e as figuras de linguagem que normalmente a sua área costuma usar. Em segundo lugar, o ponto de partida de uma análise jamais deve ser uma tese ou uma teoria insegura.

Introduzimos, assim, o pensamento de Justino de Roma e de Clemente de Alexandria. Justino é bastante sensível no que diz respeito à interação do pensamento cristão com o pensamento grego. As teorias levantadas pelos escolares e acadêmicos são boas chaves de leitura para o processo interdisciplinar da inventio, ou seja, quando Justino se dá conta que algo não pode ser explicado de alguma forma, não se sente intimidado ou obrigado a permanecer naquele lugar de investigação, procurando em outro lugar a argumentação que precisava.

As teorias, então, sugerem contrariamente uma helenização do cristianismo, em oposição a uma cristianização do mundo helênico ou a uma substituição do helenismo ou a uma instrumentalização da filosofia grega e coisas parecidas (GRIGENTI, 1995, p. 65-71). Independentemente do que signifiquem todas essas teses, é inquestionável que Justino tenha sido um exímio exemplo de interdisciplinaridade e inculturação. Sabendo que aquelas perguntas da inventio eram feitas por todos, tornava-se uma tarefa árdua discernir as várias tendências de resposta para uma mesma questão, mas de algum modo esse encontro entre o cristianismo e o helenismo favoreceu muito o pensamento filosófico da época, porque contribuiu para que os autores começassem a se abrir ao diálogo interdisciplinar.

Por sua vez, Clemente de Alexandria - que escrevera uma obra intitulada “o Pedagogo" - apresenta um esquema progressivo de ensino institucionalizado para a escola de Alexandria, no qual insiste pontualmente no caráter literário dos textos ali analisados. Seu parecer se conjugava ao fato de perceber que todos os autores de livros, em qualquer que fosse a língua, serviam-se de elementos literários para transmitir os princípios da verdade, servindo-se de enigmas, símbolos, alegorias, metáforas e outras figuras de 
gênero, por isso insistia na necessidade de aprender e ensinar tais técnicas aos seus discípulos e alunos (Stromata V, 21, 4).

Note-se o quanto Clemente de Alexandria esteja preocupado em reconhecer que entre os escritos sagrados e os escritos pagãos haja elementos formais comuns, prescindindo, à primeira vista, das verdades que esses elementos enunciam. Clemente constrói um sistema hermenêutico de interpretação das Sagradas Escrituras, assim como Filão de Alexandria tinha feito com a Torah e, antes disso, os estoicos tinham feito com os poemas homéricos a partir da alegoria (WALKER, 1985, p. 91). Todos esses autores acreditam que as figuras de gênero estivessem presentes no modo natural de falar. Por isso, tanto os poetas e filósofos quanto os profetas e, por sua vez, os apóstolos, usavam desses recursos para estabelecerem ordens consequentemente mais profundas daquilo que afirmavam. Para eles, a ordem se explicava pelo significado literário, seguido do sentido moral, culminante no sentido intelectual, que Clemente também chamava de espiritual conforme o quarto livro dos Stromata (DONALDSON, 2000, p. 303). Em Clemente de Alexandria, os elementos da inventio superavam os limites da persuasão retórica para se transformar num verdadeiro sistema gnosiológico, cujo ponto de partida era o entendimento literário como resultado da compreensão linguística.

Orígenes foi o sucessor de Clemente de Alexandria e, sem dúvida, uma das mentes mais brilhantes que a humanidade já conheceu. Com menos de 35 anos de idade, Orígenes já havia escrito uma obra hermenêutica colossal, chamada Hexapla, em que ele colocava em paralelo, em seis colunas comparativas, algumas versões em grego e em hebraico de todo o Antigo Testamento. As colunas do Hexapla eram formadas por uma versão em hebraico, uma versão hebraica transcrita foneticamente em caracteres gregos e quatro versões gregas do Antigo Testamento: os assim chamados LXX, uma versão de Áquila, outra de Símaco e, enfim, uma de Teodosiano (SALVESEN, 1998, p. 177).

Uma das motivações que levou Orígenes a produzir esta obra foi o seu interesse em descobrir o significado mais profundo das palavras e dos conceitos bíblicos (HEINE, 2010, 76). Enquanto Clemente e Orígenes decidem confiar numa solução etimológica para compreender as dificuldades iniciais da 
interpretação que deviam fazer, anos mais tarde em contexto Africano setentrional, Agostinho, depois de afirmar que grande remédio para as dificuldades encontradas seja o conhecimento de pelo menos outras duas línguas estrangeiras (De doctrina Christiana II, 11, 16), repara na existência de textos paralelos pelos quais, ao invés, se deva começar o discurso, evitando o que for obscuro e difícil, de modo que, assim, se possa introduzir enunciados claros e seguros. Eis a sua opinião em as suas próprias palavras:

[...] Este foi um fato que, ao invés de tornar-se um obstáculo, favoreceu a compreensão dos textos, tanto que o seu leitor não tenha sido uma pessoa distraída. De fato, a comparação entre muitos códigos normalmente favorece a esclarecer as frases obscuras, como o texto do profeta Isaías, que um intérprete entendeu com as seguintes palavras: "E os domésticos da tua estirpe não desprezarás", enquanto outro diz: "E não desprezarás a tua carne". Os dois, confrontados entre si, se confirmam mutuamente. Na verdade, um destes só pode ser esclarecido a partir da compreensão do outro, porque o termo "carne" poderia ser entendido em sentido próprio (literário), de modo que alguém fosse advertido a não desprezar o próprio corpo, enquanto "os domésticos da tua estirpe", com um sentido transladado (figurativo), poderiam ser os cristãos, nascidos espiritualmente da mesma semente da palavra (De Trinitate $8,7,10)$.

É possível reconhecer aqui elementos comuns àquilo que estudos recentes chamam de (epistemologia da) integração do conhecimento. Sérgio Zavaris, engenheiro civil e professor de educação integrada do Instituto Federal do Espírito Santo, propõe uma taxonomia da integração, considerando este conceito como:

uma síntese dos movimentos ocorridos na educação para promover uma formação ampliada nos diversos campos do conhecimento capaz de preparar o indivíduo para enfrentar não apenas o mundo do trabalho, mas também as demandas de uma sociedade pós-moderna complexa em um mundo de rápidas transformações (ZAVARIS, 2011, p. 201).

As dimensões apresentadas pelo prof. Zavaris sobre a taxonomia da integração em educação vão desde a perspectiva da didática, até aquela da ética, passando pela dimensão inovadora, sócio-responsável, educacional, formativa, estruturante, humanística e social (ZAVARIS, 2011, p. 207-208). Em sua avaliação conclusiva, salienta que seja extremamente recomendável que, ao lado da classificação destas dimensões, as disciplinas e os contextos 
específicos de atuação profissional se tornem a base para o desenvolvimento de uma integração do conhecimento (ZAVARIS, 2011, p. 261).

\section{Processo de aprendizagem e reconhecimento do conhecimento}

Os Padres da Igreja acreditam que a busca da sabedoria ou do conhecimento respeita um progresso sistemático, no qual, após a obtenção de uma ideia, abra-se o processo progressivo de reflexão onde se descobre significados mais profundos do que aquele entendimento inicial poderia prover. Justino de Roma refere-se à Filosofia como uma ciência do ser e do conhecimento da verdade, cujo prêmio e recompensa, conforme os grandes pensadores da antiguidade, seria a felicidade (Diálogo com Trifão 3, 4). Justino também afirma que haja várias formas de conhecimento, segundo o objeto em questão, enquanto se pode falar, em primeiro lugar, da produção de conhecimento que adquirimos através da aprendizagem, em segundo lugar, através de um treinamento aperfeiçoado, ou, enfim, através de uma visão direta ou prática (Id. 3, 6). Parece que estas indicações coincidem com as diversas vezes em que Justino relata a atividade do conhecimento adquirido pela leitura, pela prática dos costumes tradicionais e por contato mais próximo com certa realidade. Estas características podem corresponder, em Justino, àquilo que ele expressa quando explica que a atividade do conhecimento seja uma faculdade inerente da natureza humana (1 Apologia 14, 2).

Clemente de Alexandria se apresenta a favor do parecer de Platão (República V, 477a - 478d) ao declarar as três diferentes condições da mente humana, ou seja, a ignorância, o conceito e o conhecimento (Stromata VII, 100, 7). Clemente escreve seus livros a partir do julgamento preliminar pelo qual confere ao lógos (razão - Cristo) o protagonismo do crescimento do conhecimento (KINDIY, 2010, p. 286) nas três conhecidas etapas do protréptico, do pedagogo e do didáscalos.

No De Principiis, encontramos uma citação expressiva sobre a questão do processo de conhecimento, em harmonia com o que já tínhamos antes mostrado sobre a inventio, em que Orígenes aborda o nascimento da investigação da inteligência, quando diz: 
Nenhuma inteligência criada tem a possibilidade de chegar a um conhecimento absoluto, mas, desde que encontre algo do que procura, verá outras coisas a procurar; e, se chegar a essas coisas, verá muitas outras que ainda estão a procurar (De Principiis III, 26).

Mais precisas serão as palavras de Agostinho de Hipona, ao detalhar a relação entre palavra, pensamento e ensino no De Magistris:

\begin{abstract}
Quando, então, se trata dos objetos que conhecemos com a inteligência, ou seja, com um ato puro do pensamento, se exprimem conceitos de que se tem a intuição da verdade na luz interior. Por ela vem iluminado com satisfação a realidade que é considerada interior. Mesmo se, caso a pessoa que nos estiver ouvindo, contemple com puro olhar interior, essa saberá que o que digo vem do pensamento, e não das minhas palavras. Então, embora eu tenha falado de coisas verdadeiras, não ensino nem mesmo àquele que busca as coisas verdadeiras, porque não aprende por causa das minhas palavras, mas pelo próprio objeto que se manifesta à sua interioridade. Do mesmo modo, o seu conhecimento não poderia ser previsto como conclusão de um diálogo. Seria absurdo pensar que tenha sido ensinado por um discurso meu se, antes que eu tenha dito alguma coisa, eu pudesse expor-lhe, dialogando. Normalmente acontece que alguém, tendo negado algo num primeiro diálogo, seja levado a afirmar o contrário num diálogo sucessivo. O fato se verifica por causa da fraqueza de quem escuta, porque é incapaz de refletir a luz inteligível sobre a totalidade do objeto (De Magistris 12, 40, tradução nossa).
\end{abstract}

Recentemente, o Papa Francisco citou Vicente de Lerins para fundamentar o discurso sobre progresso científico na perspectiva da importância que os teólogos precisam dar, ao se comprometerem com um tipo de investigação acadêmica que gere uma contribuição efetiva para a pesquisa realizada pelas Universidades e as Faculdades Eclesiásticas (VG 3). Adverte-se que o teólogo jamais deva se contentar com o saber que possui, como se o seu pensamento estivesse completo e concluído. Corre-se o risco de promover um jeito pretencioso, arrogante e medíocre de lidar com o conhecimento científico (cf. VG 3). Por isso, Papa Francisco repete o pensamento deste autor patrístico do quinto século: "annis consolidetur, dilatetur tempore, sublimetur aetate" (Commonitorium primum 23), obrigando-nos a respeitar a trajetória temporal de um conhecimento que tende a se aperfeiçoar a cada estação da vida. De fato, é pouco provável que a consolidação, a dilatação e a conquista sublime de um conhecimento ocorra no ritmo de brevidade imposto pelo imediatismo. Para que as hipóteses se transformem em conhecimento, tem-se por requisitos, entre outras coisas essenciais, leitura, reflexão, 
amadurecimento e tempo até que o pesquisador assimile bem os resultados da sua observação. Isso vale para qualquer disciplina ou campo do saber científico.

Acreditamos que estas palavras sejam brevemente suficientes para entendermos que, na medida em que o conceito de conhecimento nos Padres da Igreja sugeria um esforço progressivo da mente, enquanto estimulava o aprendiz cada vez mais a buscar os significados profundos dos conceitos, isso fascinava e estimulava unanimemente os autores patrísticos a pensar de maneira filosófica sobre a questão do conhecimento.

\section{Ampliação do conteúdo}

Agostinho escreveu uma importante obra abordando a questão do ensino religioso, chamada De doctrina Christiana. Encontra-se, neste escrito, um vasto esforço para se compreender o método de aprendizagem dos conceitos bíblicos. Em particular, destacamos a validade dos princípios hermenêuticos que cita no terceiro livro, recuperando o ensinamento de um autor chamado Ticônio. As sete leis de interpretação do De doctrina Christiana representam, sem dúvida alguma, um passo gigantesco na investigação patrística e coincidem com as soluções inteligentes e criativas que em vários momentos estes autores ofereceram.

Como já nos ocorreu dizer anteriormente, Agostinho, introduzindo as leis de Ticônio, acredita que a explicação dos textos complexos e obscuros se reforce a partir do fundamento argumentativo daqueles textos mais claros (De doctrina Christiana III, 26, 37). Assim, a ampliação do conteúdo respeita uma ordem mais natural e menos hipotética da especulação do conteúdo.

Em três leis hermenêuticas distintas - a primeira lei, Cristo e o seu corpo; a segunda lei, as duas partes do Corpo de Cristo; a terceira lei, o diabo e o seu corpo - as soluções para os problemas epistemológicos se encontram, diríamos, na compreensão da integração do conhecimento, de maneira que a explicação de um conceito sempre requer a contextualização do argumento em um esquema disciplinar mais amplo. Por exemplo, ao longo da história da Teologia se desenvolveram duas disciplinas independentes: a Cristologia e a Eclesiologia. Segundo a aplicação da primeira lei de Ticônio seria possível dizer 
que os conceitos fundamentais de cada disciplina auxiliam o estudo para o esclarecimento necessário e para o avanço futuro dos seus conteúdos. Neste sentido, se, em virtude da complexidade do tema, não encontrarmos as respostas que buscamos quando nos perguntamos sobre um desses temas, podemos encontrar um caminho hermenêutico paralelo em outro campo hermenêutico próximo ou mesmo aparentemente contraditório, como a Medicina, a Biologia, a Sociologia etc., sem que as teorias dessas disciplinas tenham que se tornar independentes nem tão pouco autônomas.

Acreditando que a tarefa epistemológica jamais se esgota dentro de uma área específica de conhecimento, Villas Boas nota que cada área:

sempre é chamada a acompanhar novos desafios da produção de conhecimento, que não se limitam tão somente em seus elementos teóricos (teorias, métodos, distintas ênfases e perspectivas dos sujeitos epistemológicos), mas também pela influência social, cultural e política do contexto da produção do conhecimento (VILLAS BOAS, 2018, p. 270).

A terceira regra de Ticônio, sobre o espírito e a lei, introduz a questão das metáforas e dos gêneros de linguagem utilizados pelos textos religiosos (De doctrina Cristiana III, 33, 46). É importante notar como os autores cristãos reconheciam tal processo, ou seja, para eles as figuras de linguagem ocupam uma função essencial na dinâmica da fala humana. Em larga escala, esse progresso corresponde ao significado estabelecido até mesmo para aquelas ciências mais rígidas e exatas, cujas contribuições triam não apenas os melhores instrumentos para a aquisição de soluções imediatas importantíssimas, mas de elementos interdisciplinares com consequências que ultrapassam os limites de suas fórmulas e hipóteses. Em âmbito literário, por exemplo, Barba coloca-se entre a necessidade de superar a rigidez dessas fórmulas, sem o risco de perder o "rigor do ofício", constatando que as fórmulas antigas precisam passar por um programa pelo qual se revistam de novas imagens (BARBA, 2016, p.18). Todos os homens se expressam, na medida em que produzem o conhecimento, conjugando aos significados literais outros significados alegóricos paralelos. Agostinho aplica essa lei, encontrando a utilidade de partir do sentido literal para se chegar ao sentido transladado, conforme sua forma de falar, e vice-versa. 
A quarta lei de Ticônio deveria ocupar mais a nossa atenção, pois ilustra a capacidade hermenêutica de quase todo conjunto das suas normas de interpretação. Trata-se da "espécie e o gênero". Agostinho concorda com a ideia de que aquilo que foi dito sobre o todo, diz respeito também à sua parte. Muitas vezes, aquilo que foi dito em relação à parte, se esclarece quando aplicado ao todo (De doctrina Christiana III, 34, 47). Por exemplo, no direito, as normas gerais não se opõem aos princípios de aplicação da lei para a manutenção da justiça nem ao direito penal, para a correção de quem transgrida a lei. Dessa maneira, amplia-se o conhecimento da lei, quando o legislador é capaz de interpretar a justiça e a pena a partir das normas gerais do direito, assim como produz, pela jurisprudência, novos mecanismos de aplicação geral da lei. Passa-se do gênero para a espécie e da espécie para o gênero, segundo o parecer de Agostinho.

Agostinho possui uma ideia arrojada de tempo, como categoria filosófica que corresponda à memória-passado, à atenção-presente e à expectativa-futuro (Confissões XI, 14, 17). Ao mesmo tempo prevê a unidade do tempo no sujeito que faz memória, tem atenção e se inspira pela expectativa. Dessa forma, Agostinho consegue ilustrar a quinta regra de Ticônio, mostrando que, em muitos casos, os autores bíblicos usavam da sinédoque, figura de linguagem que permite tomar a parte, isto é um período de tempo, pelo todo, ou seja, todo período de tempo, e vice-versa (De doctrina Christiana III, 35, 50). Para Agostinho, quando não se tem clareza sobre algo dito, como tenha ainda que acontecer, é provável que já tenha acontecido ou que esteja acontecendo. A percepção está no sujeito.

Enfim, a sexta regra de Ticônio revela o quanto as narrativas históricas manipulam a ordem histórica segundo a perspectiva do narrador. O intérprete deve estar atento para reordenar os fatos históricos, de modo que os compreenda com mais facilidade (De doctrina Christiana III, 36, 52).

Mais do que nos preocuparmos em trazer os exemplos bíblicos apresentados por Agostinho, acreditamos que as suas reflexões sobre a interpretação dos mesmos textos sejam mais úteis, para que o estudante de hoje possa munir-se de instrumentos válidos à ampliação do conhecimento. As indicações sobre o conhecimento levantadas pelos Padres da Igreja não 
ficaram no passado, por isso também nos motivam a assumir uma postura mais aberta e interdisciplinar, como intuído pelas palavras de Barraza:

Y cuando se piensa en la importancia que dio San Agustín al estudio hasta el final de su vida, en especial la doctrina que elaboró para escudriñar las Escrituras y cómo se sirvió de las ciencias de su tiempo, hay lugar para interrogarse: ¿Qué está pasando con la formación teológica de los predicadores?... ¿Por qué no se deja transparentar una re-interpretación de la Sagrada Escritura, de la Tradición, del Magisterio y de la Doctrina Social...? ¿Por qué ese vacío? Detrás de la labor evangelizadora de san Agustín a través de sus sermones aparece una convicción profunda: ¡Que la fe nunca sea percibida como una renuncia a la inteligencia! (BARRAZA, 2014, p. 353).

\section{Considerações finais}

A origem do conhecimento é determinada pela capacidade que o aluno ou o profissional da pesquisa adquire para iniciar a sua reflexão a partir de elementos seguros oferecidos não apenas por aquelas disciplinas mais familiares a eles, mas sobretudo por aquelas que mais adequada e profissionalmente abordam a questão em pauta. Neste sentido, é indispensável maior diálogo e aceitação epistemológica entre as diversas seções do conhecimento. Concluímos que pesquisadores, leitores e os que assim buscam o conhecimento necessitam investir na primeira etapa do conhecimento, ou seja, na sua origem, construindo um mecanismo que tanto os ajude a esclarecer onde encontrarão as respostas que procuram quanto os disponha ao diálogo interdisciplinar.

Todos os autores patrísticos que citamos reconhecem no processo de assimilação das ideias a possibilidade de avanço no conhecimento, em virtude da função natural da mente em se abrir à verdade. Se não fosse por causa desse movimento natural do conhecimento no indivíduo que pesquisa ou na sociedade acadêmica, todos os esforços do saber haveriam de ser reduzidos a conceitos fossilizados e negativamente relevantes. Há, no entanto, um otimismo que nasce com aquilo que ainda deve ser compreendido, mesmo a partir dos conteúdos mais simples que já pensamos ter assimilado.

Agostinho coloca em prática e apoia o pensamento de Ticônio no que diz respeito às soluções que podem ser encontradas pelas normas hermenêuticas acima apresentadas. Nosso parecer é que a comunidade acadêmica lucraria bastante com a observação das leis retóricas como 
princípios de aperfeiçoamento do conhecimento, assim como fizeram os autores patrísticos.

\section{Referências}

AGOSTINHO. A doutrina cristã. São Paulo: Ed. Paulus, 2002.

AGOSTINHO. A Trindade. São Paulo: Ed. Paulus, 1995.

AGOSTINHO. Confissões. São Paulo: Ed. Paulus, 1997.

AGOSTINHO. Contra os Acadêmicos, A ordem, A grandeza da alma, o Mestre. São Paulo: Ed. Paulus, 2008.

BARBA, E.; MENDONÇA, P. F. Novas palavras para antigos caminhos. Poiésis, Rio de Janeiro, v.17, p. 13-20, 2016.

BARRAZA, J. M. S. Observaciones introductorias de la homilética augustiniana para la predicación atual. Atualidade Teológica, Rio de Janeiro, v. 47, p. 328-358, 2014.

CONCÍLIO VATICANO II. Decreto Optatam Totius. In: CONCÍLIO VATICANO II. Vaticano II: Constituições, Decretos, Declarações. 30. ed. Petrópolis: Editora Vozes, 2007. p. 505-526.

DONALDSON, T. Religious Rivalries and the Struggle for Success in Caesarea. Ontario: Wilfrid Laurier University Press, 2000.

FRANCISCO. Carta Apostólica Veritatis Gaudium. Sobre as Universidades e as Faculdades Eclesiásticas. São Paulo: Paulinas Editora, 2018.

GONZÁLEZ, F. J. Dialectic and Dialogue: Plato's Practice of Philosophical Inquiry. Evanston: Northwestern University Press, 1998.

GRIGENTI, G. Giustino Martire: il primo Cristiano platonico. Milano: Vita e Pensiero, 1995.

HEINE, R. E. Origen: Scholarship in the Service of the Church. Oxford: Oxford University Press, 2010.

JOÃO PAULO II. Carta encíclica sobre as relações entre fé e razão. Porto Alegre: Edipucrs, 1999.

KINDIY, O. Aproximating Church and School in Clement of Alexandria's Stomateis VII. Supplements to Vigiliae Christianae, Boston: Leiden, p. 291-298, 2010.

KOEKEMOER, L.; BIRD, S. Marketing Communications. Lansdowne: Juta and CO., 2004. 
LAUSBERG, H. Elementi di retorica. Bologna: Il Mulino, 2002.

LONERGAN, B. Insight: Uno studio del comprendere umano. Roma: Città Nuova Editrice, 2007.

LONGOBARDO, L. Mia sola arte è la fede: Paolino di Nola teólogo sapienziale. Napoli: Eurocomp, 2000.

ORÍGENES. Tratado sobre os princípios. São Paulo: Ed. Paulus, 2012.

REBOUL, O. Introduzione alla retorica. Bologna: II Mulino, 2003.

SALVESEN, A. Origen's Hexapla and Fragments. Philadelphia: Coronet Books, 1998.

VALENTIM, M. Gestão, mediação e uso da informação. São Paulo: Editora Unesp, 2010.

VILLAS BOAS, A. Perspectiva interdisciplinar da teologia no Brasil: o debate epistemológico da Área da Ciência da Religião e Teologia. Interações, Belo Horizonte, v. 13, n. 24, pp. 260-286, 2018.

WALKER, W. A History of the Christian Church. New York: Scribner, 1985.

ZAVARIS, S. C. Epistemología de la integración del conocimiento: un estudio de caso sobre el uso de la casa modelo como objeto pedagógico para colaboración de las dimensiones de integración del conocimiento en el curso técnico de construcción PROEJA-IFES. Tese (Doutorado en Educação) - Viña del Mar, Universidad del Mar, 2011. 